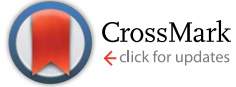

Cite this: RSC Adv., 2017, 7, 9803

Received 18th November 2016 Accepted 17th January 2017

DOI: $10.1039 / c 6 r a 26968 k$

rsc.li/rsc-advances

\section{Nano-montmorillonite modified foamed paste with a high volume fly ash binder}

\author{
Zhipeng Li, ${ }^{a}$ Jing Gong, ${ }^{\star a b}$ Sen Du, ${ }^{c}$ Jianlin $\mathrm{Wu}^{,}{ }^{\mathrm{a}}$ Jianfen $\mathrm{Li}^{\mathrm{d}}{ }^{\mathrm{d}}$ Daniel Hoffman ${ }^{\mathrm{c}}$ \\ and Xianming Shi ${ }^{\star a c}$
}

This laboratory study explores a cost-effective and environmental friendly foamed paste with satisfactory physical properties and outstanding thermal insulation properties. Such a composite material was made by using a high volume of class F coal fly ash as a replacement of Portland cement ( $70 \%$ by mass) and nano-montmorillonite as an admixture. Replacing cement with fly ash at high levels is environmentally and economically desirable, as this not only reduces the energy and carbon footprint of the foamed paste, but also diverts the coal fly ash from the waste stream. A statistical design of experiments was adopted and executed to investigate the effects of various factors on the properties of the composite. At the age of 28 days, the pastes exhibited a high compressive strength ranging from $1.77 \mathrm{MPa}$ to $6.51 \mathrm{MPa}$ and a low thermal conductivity in the range of $0.071 \mathrm{~W}\left(\mathrm{~m}^{-1} \mathrm{~K}^{-1}\right)$ to $0.173 \mathrm{~W}\left(\mathrm{~m}^{-1} \mathrm{~K}^{-1}\right)$. Two foamed mixes were chosen for further investigation as they presented the best and worst performance as a thermal insulation material. The scanning electron microscopy shed light on the best foamed mix, which contains $70 \%$ fly ash, 30\% cement, and 1\% nano-montmorillonite, and how its microstructure differed from that of the worst mix without nano-montmorillonite. The Ca content, Si/Ca ratio and $\mathrm{Al} / \mathrm{Ca}$ ratio were obtained from energy-dispersive X-ray spectroscopy of hardened samples, and used to help explain the observed strength difference between these two mixes. X-ray diffraction was also employed to elucidate the hydration mechanism of HVFC foamed paste.

\section{Introduction}

Organic thermal insulation materials (TIMs) have been widely used in developing countries. Yet, they are known as the most dangerous source of fire hazard in buildings, especially in highrise buildings where it is very difficult to douse fire from the ground. ${ }^{1}$ The inherent drawbacks of traditional organic TIMs highlight the urgent need to develop alternative TIMs that are nonflammable, light-weight, and sufficiently strong.

Foamed paste and foamed concrete have attracted much attention as a type of promising TIM, in light of the inorganic, non-flammable, and porous properties of these cementitious materials. $^{2-6}$ Typically, a foaming method is employed to introduce high porosity into such composite materials, resulting in a thermal conductivity ranging from $0.15 \mathrm{~W} \mathrm{~m}^{-1} \mathrm{~K}^{-1}$ to

${ }^{a}$ School of Civil Engineering and Architecture, Wuhan Polytechnic University, Wuhan 430023, China. E-mail: gongjingshao@163.com; xianming.shi@wsu.edu ${ }^{b}$ College of Urban Construction, Wuchang University of Technology, Wuhan 430223, China

'Laboratory for Advanced \& Sustainable Cementitious Materials, Department of Civil and Environmental Engineering, Washington State University, Pullman, WA 99164, USA

${ }^{d}$ School of Chemical Engineering and Environment, Wuhan Polytechnic University, Wuhan 430023, China
$0.45 \mathrm{~W} \mathrm{~m}^{-1} \mathrm{~K}^{-1}$ and a compressive strength ranging from about 1.5 $\mathrm{MPa}$ to $6.5 \mathrm{MPa}^{.-12}$

The main raw material of the inorganic TIMs is Portland cement, the production of which is known to pose many concerns to environmental sustainability, including highenergy consumption, the release of air pollutants such as $\mathrm{N}_{X} \mathrm{O}_{Y}$ and $\mathrm{SO}_{2}$, and the emission of greenhouse gases such as $\mathrm{CO}_{2}$. Fly ash, a main by-product of coal-fired power plants, has become one of the most used supplementary cementitious materials (SCMs) in concrete industry. ${ }^{13-16}$ Using fly ash as a SCM can not only reduce the carbon footprint and embodied energy of the concrete, but also reduce the hazards it may bring to the environment. ${ }^{17}$

Coal fly ash is one of the most complex anthropogenic materials. ${ }^{17}$ While conventional practices have limited the replacement of cement by coal fly ash to no more than $30 \mathrm{wt} \%$ to ensure the strength and durability properties of concrete, ${ }^{\mathbf{1 8}}$ recent years have seen replacement levels between $50 \%$ and $80 \%$, i.e., high volume fly ash (HVFA) concretes. HVFA concretes can be used in structural projects providing good workability, high mechanical strength, and durability comparable to ordinary Portland cement (OPC) concrete. ${ }^{19-21}$ Numerous studies have reported that the HVFA concrete featured a reduced water and gas permeability relative to its OPC counterpart. ${ }^{22-24}$ Yet, little research has been reported to elucidate the mechanisms 
underlying the hydration process of HVFA foamed paste or its microstructure.

In this context, this laboratory study aims to explore the feasibility of using a HVFA binder to produce foamed paste for TIM applications. To further improve the performance of foamed paste, this study investigates the potential benefits of incorporating nano-montmorillonite (nMMT) as an admixture. Compared with other nanomaterials, nMMT features great absorption and cation exchange capacity (due to its special nanosheets structure) and is more affordable and environmentally sustainable.

Using HVFA binder in foamed paste is environmentally and economically desirable, as this not only reduces the energy and carbon footprints of the foamed paste, but also diverts the coal fly ash from waste stream. This study also helps to achieve indepth understanding of the hydration of nMMT-modified HFVA foamed paste.

\section{Experimental}

\section{Materials}

The cementitious binder used to fabricate the foamed paste samples featured a mixture of coal fly ash and Portland cement. The Portland cement was obtained from Cement Co., Ltd of Gezhouba Group (Hubei, China) and is categorized as PO42.5 cement per the Chinese National Standard GB175-2007. The class F fly ash (FA) was obtained from National Electric Power Co., Ltd. (Wuhan, China), mainly consisting of spherical particles as shown in Fig. 1. The chemical composition of cement and FA is provided in Table 1.

The foaming agents used were sodium alpha-olefin sulfonate (AOS) and alcohol ethoxylate (AEO), whose characteristics are provided in Table 2 . Both of the foaming agents were produced
Table 2 Characteristics of AOS and AEO

\begin{tabular}{llllll}
\hline Agent & Character & $\begin{array}{l}\text { Molecular } \\
\text { weight }\end{array}$ & $\begin{array}{l}\text { Active } \\
\text { ingredient }\end{array}$ & $\mathrm{Na}_{2} \mathrm{SO}_{4}$ & $\begin{array}{l}\text { Free } \\
\text { alkali }\end{array}$ \\
\hline AOS & White powder & 341 & $91.1 \%$ & $2.3 \%$ & $0.2 \%$ \\
AEO & Colorless oil & 319 & $85.7 \%$ & $3.0 \%$ & $0.2 \%$ \\
\hline
\end{tabular}

by Guangzhou Sui Xin Chemical Co., Ltd., China. The stabilizing agent used was sodium phosphate $\left(\mathrm{Na}_{3} \mathrm{PO}_{4}\right.$, purity 99.5\%), which was produced by Tianjin FuChen Chemical Reagent Factory, China.

The nano-montmorillonite (nMMT) used was produced by Zhejiang FengHong New Materials Co., Ltd., which has a purity of $99.5 \%$ (Technical Grade) and features an apparent density of $0.35 \mathrm{~g} \mathrm{~cm}^{-3}$. The nMMT is hydrophilic and features high aspect ratio and a platelet structure, with each platelet less than $25 \mathrm{~nm}$ thick. The molecular diagram and reduced graph of such material are shown in Fig. $2 .^{25}$

\section{Experimental design}

A statistical design of experiments, Uniform Design, ${ }^{26}$ was employed to evaluate the influence of mix design parameters on the compressive strength and thermal conductivity of the foamed paste. Also known as Space Filling Design, this experimental design method was proposed by Fang in 1978 (ref. 26) as an application of "pseudo-Monte Carlo method", which focuses on the uniformity of data points in the test domain in order to obtain the most information through the least number of tests. This method considers only the test points spread evenly in the test range and are thus statistically representative via "uniform dispersion", rather than "neat and comparable".

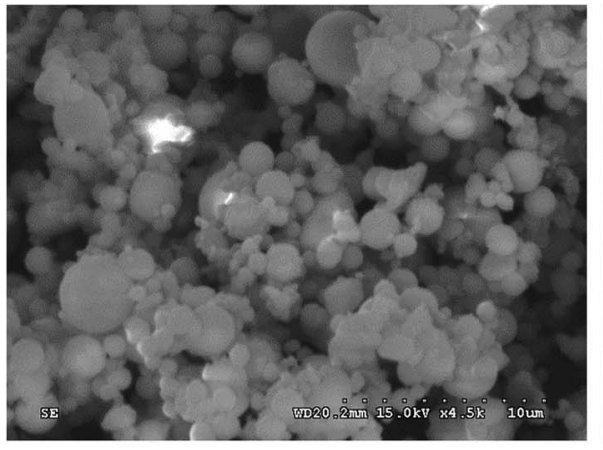

(a)

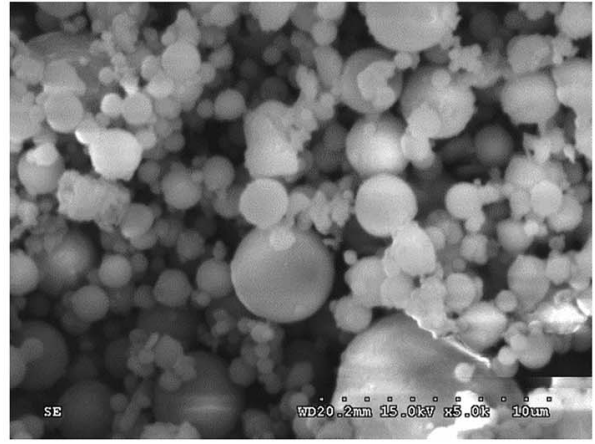

(b)

Fig. 1 Scanning electron microscope (SEM) micrographs of the coal fly ash at two magnification levels: (a) 4500 times; (b) 5000 times.

Table 1 Chemical composition of Portland cement and FA (provided by the vendors, via analysis by X-ray florescence)

\begin{tabular}{|c|c|c|c|c|c|c|c|c|c|c|}
\hline Binder type & Composition & $\mathrm{SiO}_{2}$ & $\mathrm{Al}_{2} \mathrm{O}_{3}$ & $\mathrm{Fe}_{2} \mathrm{O}_{3}$ & $\mathrm{CaO}$ & $\mathrm{MgO}$ & $\mathrm{Na}_{2} \mathrm{O}$ & $\mathrm{K}_{2} \mathrm{O}$ & $\mathrm{SO}_{3}$ & $\mathrm{LOI}^{a}$ \\
\hline Portland cement & Content (wt\%) & 20.23 & 5.24 & 2.89 & 61.13 & 2.08 & 0.77 & 1.22 & 2.50 & 0.42 \\
\hline Class F FA & & 55.91 & 30.18 & 4.92 & 2.39 & 0.37 & 0.35 & 1.65 & 0.49 & 2.89 \\
\hline
\end{tabular}

${ }^{a}$ Measured by following the ASTM D7348 - 13: Standard Test Methods for Loss on Ignition (LOI) of solid combustion residues. 


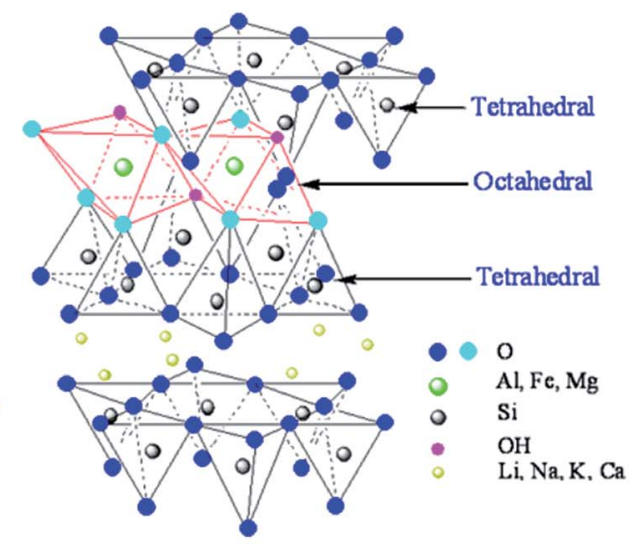

(a)

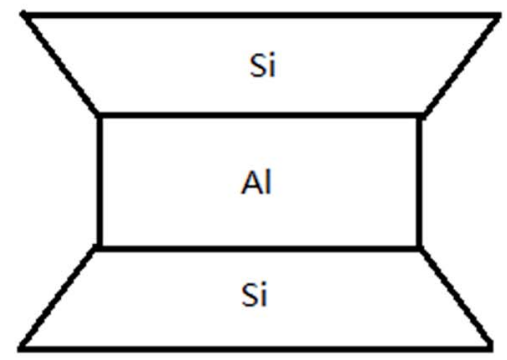

(b)

Fig. 2 Molecular diagram (a) and reduced graph (b) of nMMT. ${ }^{25}$

As shown in Table 3, the design scheme considered five factors, i.e., $\mathrm{x}_{1}$ (level of replacing cement by $\mathrm{FA}$ ), $\mathrm{x}_{2}$ (AOS dosage), $\mathrm{X}_{3}$ (AEO dosage), $\mathrm{X}_{4}\left(\mathrm{Na}_{3} \mathrm{PO}_{4}\right.$ dosage), and $\mathrm{X}_{5}$ (nMMT dosage), each at three levels. Table 4 presents the uniform design scheme used, with a total of 18 runs, each representing a unique mix design of the foamed paste. For the samples, a water/binder ratio of 0.30 was used and the water used as tap water from Wuhan, China.

\section{Sample fabrication}

The process of fabricating the foamed paste samples is illustrated in Fig. 3. A total $1000 \mathrm{~g}$ of cement and fly ash was first drymixed in a mixer with a low stirring speed of about $500 \mathrm{rpm}$ for $1 \mathrm{~min}$. Then $100 \mathrm{ml}$ water was poured into the dry mixture for another $1 \mathrm{~min}$ of mixing to make it moist. Subsequently, another $100 \mathrm{ml}$ water containing the designed amount of AOS, AEO, $\mathrm{Na}_{3} \mathrm{PO}_{4}$, and nMMT was poured into the mixture and mixed for $1 \mathrm{~min}$ at about $1000 \mathrm{rpm}$. Note that these foaming agents and stabilizing agent had been dissolved in the water and used to soak the nMMT for $24 \mathrm{~h}$ to facilitate its dispersion. At last, the remaining $100 \mathrm{ml}$ water was used to rinse any residual agents out of the water container and mixed for $3 \mathrm{~min}$ at about $1000 \mathrm{rpm}$. This made the mixture into an apparently homogeneous and flowable slurry, which was then cast into the steel (or polyvinyl chloride) molds, as shown in Fig. 3. The paste samples (both prisms and cylinders) were covered with a plastic membrane, demolded at $24 \mathrm{~h}$, and then cured in a controlled environment (temperature: $20 \pm 2{ }^{\circ} \mathrm{C}$, relative humidity: 95\%) for $7 \mathrm{~d}$ or $28 \mathrm{~d}$. Before testing their engineering properties, the hardened samples were dried for $24 \mathrm{~h}$ at ambient temperature $\left(20 \pm 2{ }^{\circ} \mathrm{C}\right)$ and relative humidity $50 \%$.

\section{Testing of engineering properties}

For each mix design, six cylinder samples $100 \mathrm{~mm}$ in height and $100 \mathrm{~mm}$ in diameter were cast for the compressive strength test, which was conducted using an electro-hydraulic servo compression test machine (Fig. 4) with a loading speed of $0.1 \mathrm{MPa} \mathrm{s}^{-1}$. For each mix design, two prism samples with the dimension of $300 \mathrm{~mm} \times 300 \mathrm{~mm} \times 30 \mathrm{~mm}$ were cast for the thermal conductivity test, which was conducted using a PDR300 thermal conductivity measurement device (Fig. 4), with the initial and final temperatures set at $20{ }^{\circ} \mathrm{C}$ and $60{ }^{\circ} \mathrm{C}$, respectively. The accuracy of the machine was $\pm 0.01 \mathrm{~W}\left(\mathrm{~m}^{-1}\right.$ $\mathrm{K}^{-1}$ ) and the thermal conductivity of the duplicate samples exhibited very high reproducibility, all within the range of $\pm 0.07 \mathrm{~W}\left(\mathrm{~m}^{-1} \mathrm{~K}^{-1}\right)$.

\section{Advanced characterization}

The surface morphology of the fly ash was observed by SEM, performed on a HITACHI S-3000N (Japan) scanning electron microscope, using an acceleration voltage of $15 \mathrm{kV}$. The same machine and setting were employed to examine the surface

Table 3 The factors and their levels explored in the uniform design scheme

\begin{tabular}{|c|c|c|c|c|c|}
\hline \multirow[b]{3}{*}{ Levels } & \multicolumn{5}{|l|}{ Factors } \\
\hline & $\mathrm{X}_{1}$ & $\mathrm{X}_{2}$ & $\mathrm{X}_{3}$ & $\mathrm{X}_{4}$ & $\mathrm{X}_{5}$ \\
\hline & FA/total binder & $\begin{array}{l}\text { AOS/total } \\
\text { binder }\end{array}$ & AEO/total binder & $\begin{array}{l}\mathrm{Na}_{3} \mathrm{PO}_{4} / \text { total } \\
\text { binder }\end{array}$ & $\begin{array}{l}\mathrm{nMMT} / \text { total } \\
\text { binder }\end{array}$ \\
\hline 1 & $60 \%$ & 0 & 0 & 0 & 0 \\
\hline 2 & $70 \%$ & $1 \%$ & $1 \%$ & $0.38 \%$ & $1 \%$ \\
\hline 3 & $80 \%$ & $2 \%$ & $2 \%$ & $0.75 \%$ & $2 \%$ \\
\hline
\end{tabular}


Table 4 The uniform design scheme used

\begin{tabular}{|c|c|c|c|c|c|}
\hline Run no. & Factor $\mathrm{X}_{1}$ level & Factor $\mathrm{X}_{2}$ level & Factor $\mathrm{X}_{3}$ level & Factor $\mathrm{X}_{4}$ level & Factor $\mathrm{X}_{5}$ level \\
\hline 1 & 1 & 1 & 1 & 1 & 3 \\
\hline 2 & 1 & 3 & 3 & 3 & 3 \\
\hline 3 & 1 & 2 & 2 & 2 & 2 \\
\hline 4 & 1 & 2 & 3 & 1 & 1 \\
\hline 5 & 1 & 1 & 2 & 3 & 1 \\
\hline 6 & 1 & 3 & 1 & 2 & 3 \\
\hline 7 & 2 & 2 & 3 & 1 & 2 \\
\hline 8 & 2 & 3 & 2 & 2 & 3 \\
\hline 9 & 2 & 1 & 3 & 1 & 2 \\
\hline 10 & 2 & 1 & 2 & 3 & 1 \\
\hline 11 & 2 & 2 & 1 & 3 & 1 \\
\hline 12 & 2 & 3 & 1 & 2 & 3 \\
\hline 13 & 3 & 3 & 2 & 1 & 1 \\
\hline 14 & 3 & 1 & 1 & 3 & 2 \\
\hline 15 & 3 & 2 & 1 & 3 & 3 \\
\hline 16 & 3 & 3 & 3 & 1 & 3 \\
\hline 17 & 3 & 2 & 2 & 2 & 2 \\
\hline 18 & 3 & 1 & 3 & 2 & 1 \\
\hline
\end{tabular}

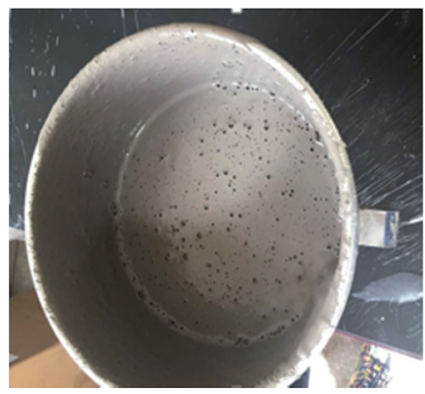

(a)

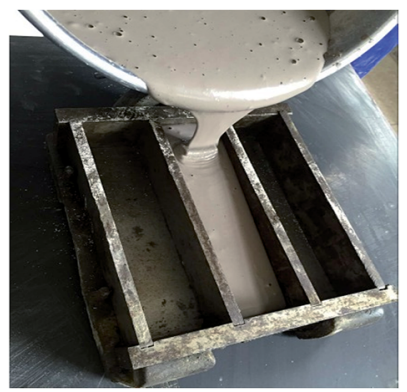

(b)

Fig. 3 The fresh slurry HVFA mixture (a) being cast into molds (b).

morphology of the microstructure of the selected paste sample at a low magnification level (e.g., 40×). A different scanning electron microscope, FEI HELIOS NanoLab 600i (Oregon, USA), was employed to examine the same paste samples at higher resolutions, using an acceleration voltage of $20 \mathrm{kV}$. This machine was also equipped to enable energy dispersive X-ray spectroscopy (EDX), a microanalytical unit for detection of

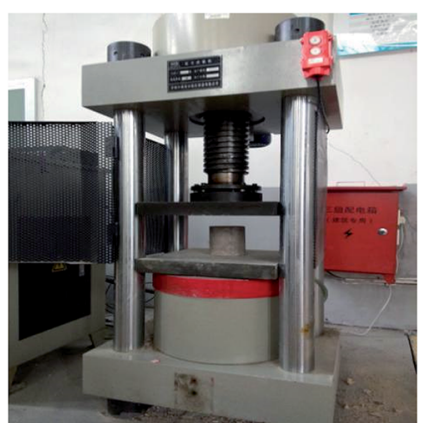

(a)

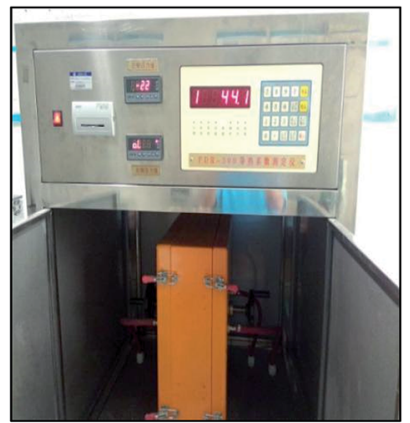

(b)
Fig. 4 Computer-controlled compression test machine (a) and thermal conductivity measurement device (b). small variations in trace element content, using an accelerating voltage of $20 \mathrm{kV}$ and a scan time of $60 \mathrm{~s}$ per sampling area. X-ray diffraction (XRD) patterns of the fly ash and selected paste specimens were obtained on a D8 ADVANCE X-ray diffractometer manufactured by Bruker Technology Co., Ltd. (Wisconsin, USA) with $\mathrm{Cu} \mathrm{K} \alpha$ radiation $(\lambda=1.54 \AA$ ).

\section{Results and discussion}

\section{Engineering properties of foamed paste}

Experimental results of $7 \mathrm{~d}$ and $28 \mathrm{~d}$ compressive strength (CS) and $28 \mathrm{~d}$ thermal conductivity (TC) of the hardened foamed paste samples are presented in Table 5 . The results suggest that the mix design plays a significant role in defining these engineering properties. The $7 \mathrm{~d}$ compressive strength of HVFC pastes ranged from $0.95 \mathrm{MPa}$ to $4.01 \mathrm{MPa}$. At the age of 28 days, the HVFC pastes exhibited a high compressive strength ranging from 1.77 MPa to 6.51 MPa and a low thermal conductivity in the range of $0.071 \mathrm{~W}\left(\mathrm{~m}^{-1} \mathrm{~K}^{-1}\right)$ to $0.173 \mathrm{~W}\left(\mathrm{~m}^{-1} \mathrm{~K}^{-1}\right)$. Note that the non-foamed Portland cement paste (water/binder ratio of 0.30) exhibited a $28 \mathrm{~d}$ compressive strength of $52.5 \mathrm{MPa}$ and a thermal conductivity of $0.453 \mathrm{~W}\left(\mathrm{~m}^{-1} \mathrm{~K}^{-1}\right)$. It was infeasible to produce foamed pastes using either the cement or the fly ash as the sole binder.

Mix \#1 (with 60\% FA and 2\% nMMT and no other agents) exhibited the highest strength and thermal conductivity values, due to the absence of foaming agents and thus the formation of least porous microstructure. Mix \#7 (with 70\% FA, 1\% AOS, 2\% AEO, $0.75 \% \mathrm{Na}_{3} \mathrm{PO}_{4}$, and 1\% nMMT) exhibited the lowest thermal conductivity yet reasonably high strength values, representing the best TIMs among the mixtures investigated. Mix \#13 (with $80 \%$ FA, 2\% AOS, $1 \%$ AEO, no $\mathrm{Na}_{3} \mathrm{PO}_{4}$ or nMMT) exhibited the nearly lowest thermal conductivity but lowest strength values, representing the worst TIMs.

The experimental results were processed using multiregression analysis, which aimed to correlate the $\mathrm{CS}_{7} \mathrm{~d}, \mathrm{CS}_{28}$ 
Table 5 Compressive strength and thermal conductivity of the foamed paste samples

\begin{tabular}{|c|c|c|c|c|c|c|c|c|c|}
\hline Run No. & 1 & 2 & 3 & 4 & 5 & 6 & 7 & 8 & 9 \\
\hline $\mathrm{CS}_{7 \mathrm{~d}}(\mathrm{MPa})$ & 4.01 & 2.31 & 2.74 & 1.63 & 2.81 & 2.94 & 2.23 & 2.53 & 2.41 \\
\hline $\mathrm{CS}_{28 \mathrm{~d}}(\mathrm{MPa})$ & 6.51 & 3.01 & 4.27 & 2.73 & 5.64 & 4.37 & 3.23 & 3.08 & 4.24 \\
\hline $\mathrm{TC}_{28 \mathrm{~d}}\left(\mathrm{~W} \mathrm{~m}{ }^{-1}{ }^{\circ} \mathrm{C}^{-1}\right)$ & 0.173 & 0.073 & 0.099 & 0.073 & 0.125 & 0.100 & 0.071 & 0.072 & 0.099 \\
\hline Run No. & 10 & 11 & 12 & 13 & 14 & 15 & 16 & 17 & 18 \\
\hline $\mathrm{CS}_{7 \mathrm{~d}}(\mathrm{MPa})$ & 2.63 & 2.59 & 2.71 & 0.95 & 3.72 & 3.22 & 1.45 & 1.94 & 1.42 \\
\hline $\mathrm{CS}_{28 \mathrm{~d}}(\mathrm{MPa})$ & 5.12 & 4.48 & 3.44 & 1.77 & 6.30 & 4.77 & 2.34 & 3.31 & 3.23 \\
\hline
\end{tabular}

$\mathrm{d}$, and $\mathrm{TC}_{28 \mathrm{~d}}$ with the five mix design parameters, respectively. Three predictive equations were established as follows:

$$
\begin{aligned}
\mathrm{CS}_{7 \mathrm{~d}}= & 4.81-0.04 x_{1}-1.92 x_{2}+2.29 x_{5}+0.02 x_{1} x_{2}+0.02 x_{1} x_{4} \\
& -0.02 x_{1} x_{5}-0.91 x_{3} x_{4} \\
\mathrm{CS}_{28 \mathrm{~d}}= & 8.05-0.06 x_{1}-3.58 x_{2}+4.29 x_{5}+0.04 x_{1} x_{2}+0.05 x_{1} x_{4} \\
& -0.05 x_{1} x_{5}-1.18 x_{2} x_{4}-1.14 x_{3} x_{4} \\
& \mathrm{TC}_{28 \mathrm{~d}}=0.1493-0.023 x_{2}-0.024 x_{3}
\end{aligned}
$$

The predicted values agreed very well with the experimental values, with a very high coefficient of correlation $\left(R^{2}\right)$ between them. The $R$-square was $0.85,0.98$, and 0.89 , for $\mathrm{CS}_{7 \mathrm{~d}}, \mathrm{CS}_{28 \mathrm{~d}}$, and $\mathrm{TC}_{28} \mathrm{~d}$, respectively. Furthermore, good precision and confidence were found from these predictive models, the $p$ value of which was significantly smaller than 0.05 . As such, the established models can be used to illustrate the effect of significant factors on the response variable of interest. For instance, from the $\mathrm{TC}_{28}$ d model, one can conclude that the thermal conductivity of the foamed paste decreased linearly with the use of each foaming agent but was not significantly affected by the dosage of FA, $\mathrm{Na}_{3} \mathrm{PO}_{4}$, or nMMT in the mix.

\section{$28 \mathrm{~d}$ compressive strength as a function of mix design}

This section is devoted to understanding the $28 \mathrm{~d}$ compressive strength as a function of mix design of the pastes. This is necessary considering the existence of two-way interactions in the predictive equation for $\mathrm{CS}_{28}$ d. Fig. 5 presents some threedimensional (3D) contour plots (left) to illustrate how $\mathrm{CS}_{28} \mathrm{~d}^{-}$ changes with variations in two selected factors of the foamed paste, with the other three design factors fixed at a certain level. Note that a corresponding contour map (right) is provided to supplement each 3D contour plot to make it clearer.

Fig. 5 clearly illustrates the dependence of $28 \mathrm{~d}$ compressive strength of the foamed paste on four key design factors: the dosage of FA, AOS, $\mathrm{Na}_{3} \mathrm{PO}_{4}$, and nMMT. Fig. 8a shows that $\mathrm{CS}_{28}$ ${ }_{d}$ increases with the use of a lower FA replacement level and a lower AOS dosage, with other factors fixed at a medium level. Fig. 8b shows that $\mathrm{CS}_{28}$ d increases with the use of a lower FA replacement level and a higher nMMT dosage, with other factors fixed at a medium level. Fig. 8c shows that $\mathrm{CS}_{28} \mathrm{~d}^{-}$ increases with the use of a lower FA replacement level and a higher $\mathrm{Na}_{3} \mathrm{PO}_{4}$ dosage, with other factors fixed at a medium level. The detrimental effect of AOS on the compressive strength of HVFC foamed paste is attributable to the introduction of porosity by AOS. The beneficial effect of $\mathrm{Na}_{3} \mathrm{PO}_{4}$ on the compressive strength of HVFC foamed paste is possibly attributable to the activation of fly ash particles by this alkaline substance.

To confirm the beneficial role of admixing nMMT in the compressive strength of hardened HVFC foamed paste, a new set of laboratory experiments were conducted as follows. Starting from the two selected mixes (\#7 and \#13), four other mixes were fabricated to vary the nMMT content $(0 \%, 1 \%, 2 \%, 3 \%$, and $4 \%$, by mass of total binder) while keeping other design factors unchanged. As illustrated in Fig. 6, in both cases, $\mathrm{CS}_{28}$ ${ }_{d}$ increased with the increase in the nMMT dosage from $0 \%$ to $3 \%$ and then slightly decreased once the nMMT dosage further increased from $3 \%$ to $4 \%$. This observed trend coincided with another study, where admixing another type of nanoclay (halloysite) up to $3 \%$ by mass of cement increased the 28 d compressive strength of cement mortars. ${ }^{27}$ In yet another study, ${ }^{28}$ the $28 \mathrm{~d}$ compressive strength of cement pastes increased with the dosage of admixed nMMT but the trend reversed once the nMMT dosage was over $0.6 \%$ by mass of cement. The difference of the optimum nMMT is attributable to the difference between foamed paste and ordinary paste.

The beneficial effect of nMMT on the compressive strength of HVFC foamed paste could be attributable to multiple mechanisms. For instance, previous studies ${ }^{28-30}$ have revealed that nMMT can significantly improve the properties and performance of concrete by acting as nanofiller and as 'nucleus' to guide the formation and growth of cement hydration products, participating in the pozzolanic reaction, exfoliating its nanosheets, etc. In addition, the Si-O and $\mathrm{Al}-\mathrm{O}$ bonds in nMMT might act with cement particles, accelerating the cement hydration and producing more of C-S-H hydrates. ${ }^{27}$

The adverse effect of admixing too much nMMT on the strength of hardened HVFC foamed paste is likely attributable to the great hydrophilicity and water demand of nMMT, which takes a large portion of the mixing water away from cement and fly ash particles and results in their insufficient hydration. A separate laboratory experiment demonstrated that nMMT expanded significantly as a result of water absorption. This is related to its negatively charged nanosheets that attract the polar water molecules into their interlayer space. The expansion of the lamellar spacing then increases the volume of watersoaked nMMT. ${ }^{29}$ 


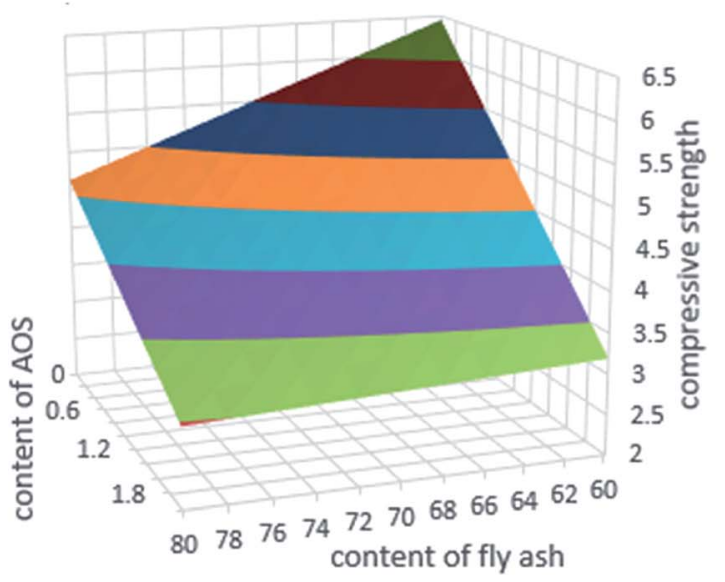

(a)

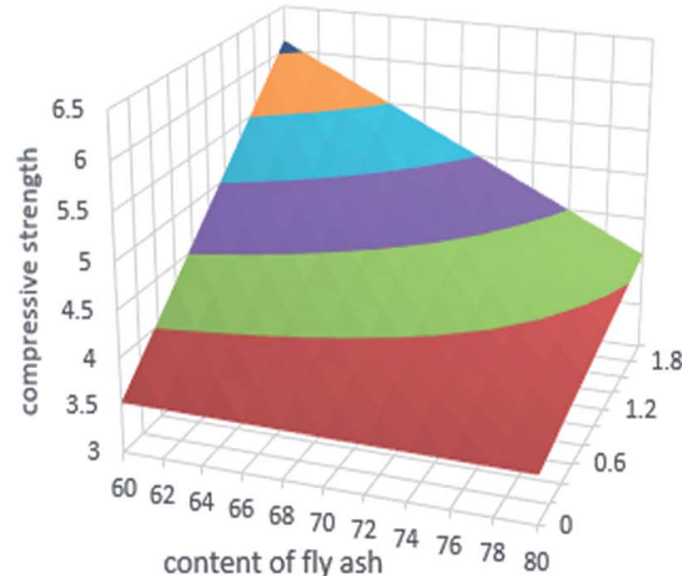

(b)

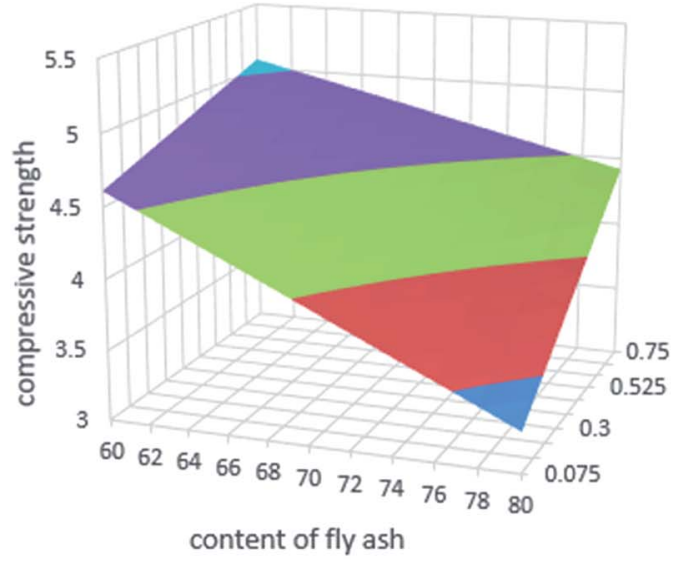

(c)

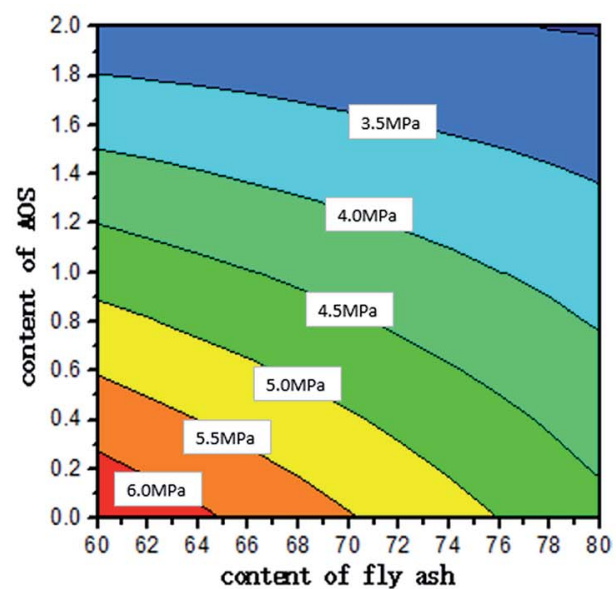

content of fly ash
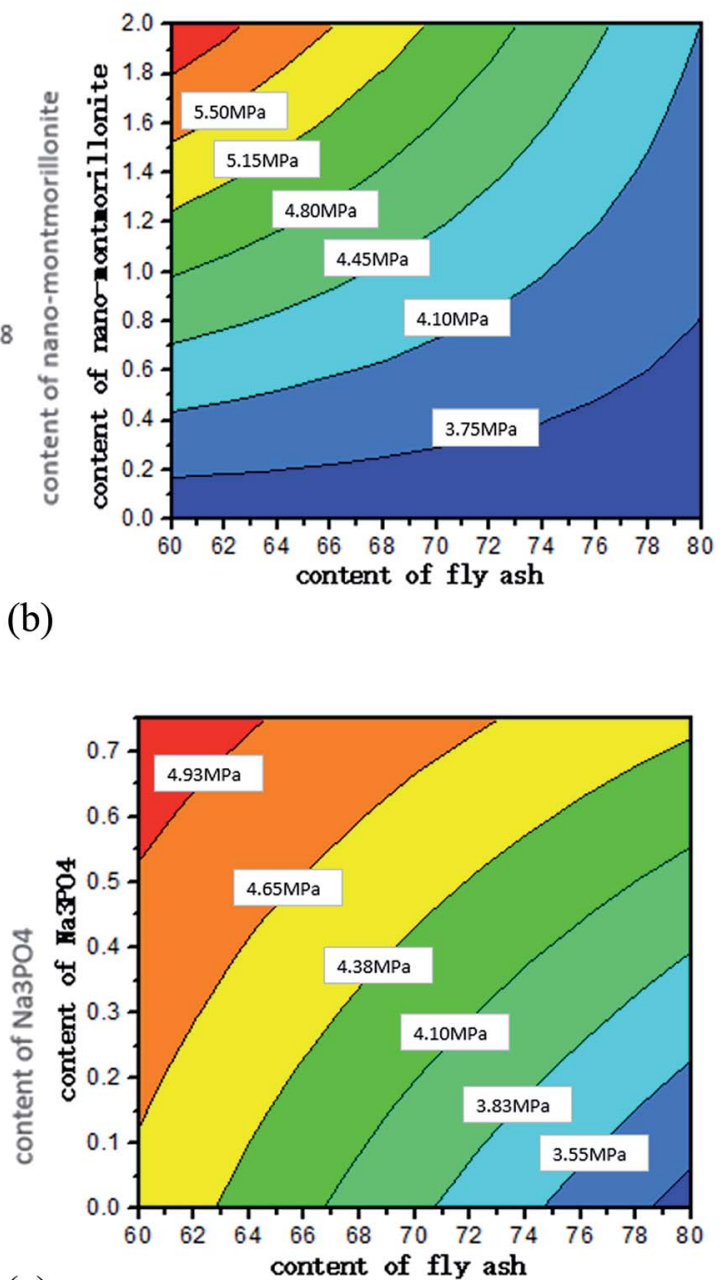

Fig. 5 Relationships between 28 d compressive strength and (a) FA and AOS dosages (with $1 \%$ AEO, $0.38 \% \mathrm{Na}_{3} \mathrm{PO}_{4}$ and $1 \%$ nMMT); (b) FA and nMMT (with 1\% AEO, 1\% AOS and 0.38\% Na $\mathrm{NO}_{4}$ ); (c) FA and $\mathrm{Na}_{3} \mathrm{PO}_{4}$ (with 1\% AEO, 1\% AOS, and 1\% nMMT).

\section{Microstructure and hydration analyses of foamed paste}

The microstructure of the selected foamed paste samples was examined using SEM and the results are provided in Fig. 7. At the magnifications of 40 times, it can be found the structure in the hardened mix \#7 (Fig. 7a) was more homogeneous than that in hardened mix \#13 (Fig. 7b), which helps explain its higher 28 


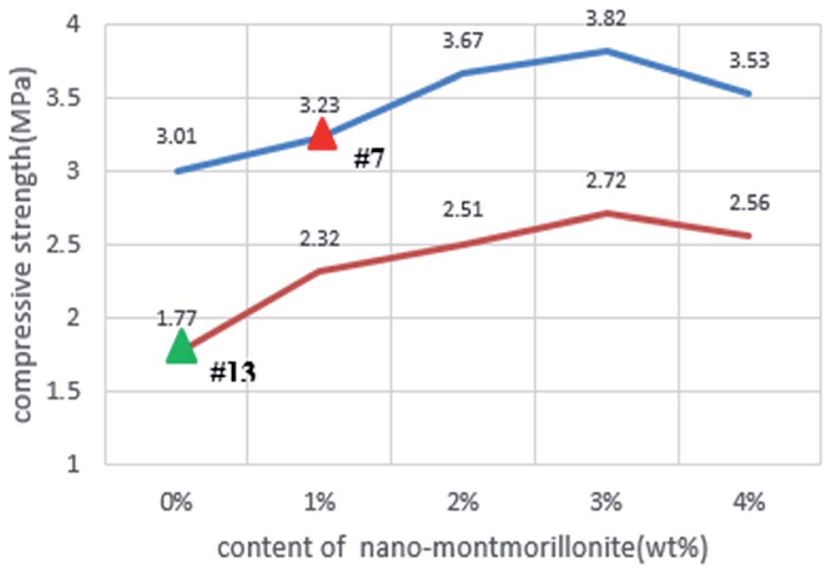

Fig. 6 The role of nMMT in changing the $28 \mathrm{~d}$ compressive strength of foamed pastes.

d compressive strength. Moreover, at the magnifications of 7000 times, the microstructure of mix \#7 (Fig. 7c) featured more crystalline phases than that of mix \#13 (Fig. 7d).

The elemental composition distribution of the selected foamed paste samples was examined using EDX, by collecting the data

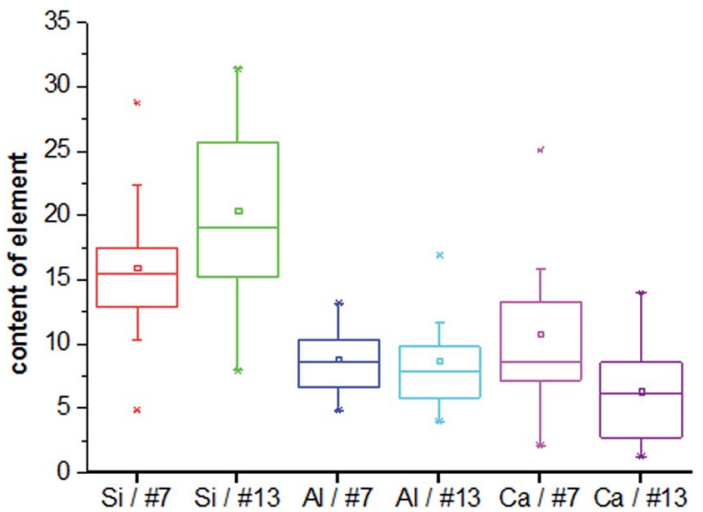

Fig. 8 Box plots of key elemental contents in the hardened mixes \#7 and \#13.

from ten non-overlapping sites randomly selected from the SEM of each mix. These EDX data were further investigated in the form of key elemental contents (Fig. 8) and molar ratios of Si/Ca and Al/Ca (Fig. 9), shown as box plots to illustrate the variability of each. ${ }^{31} \mathrm{As}$ can be seen in Fig. 8, mix \#7 exhibited significantly higher $\mathrm{Ca}$ and lower Si content but similar Al content than mix \#13. As such, mix
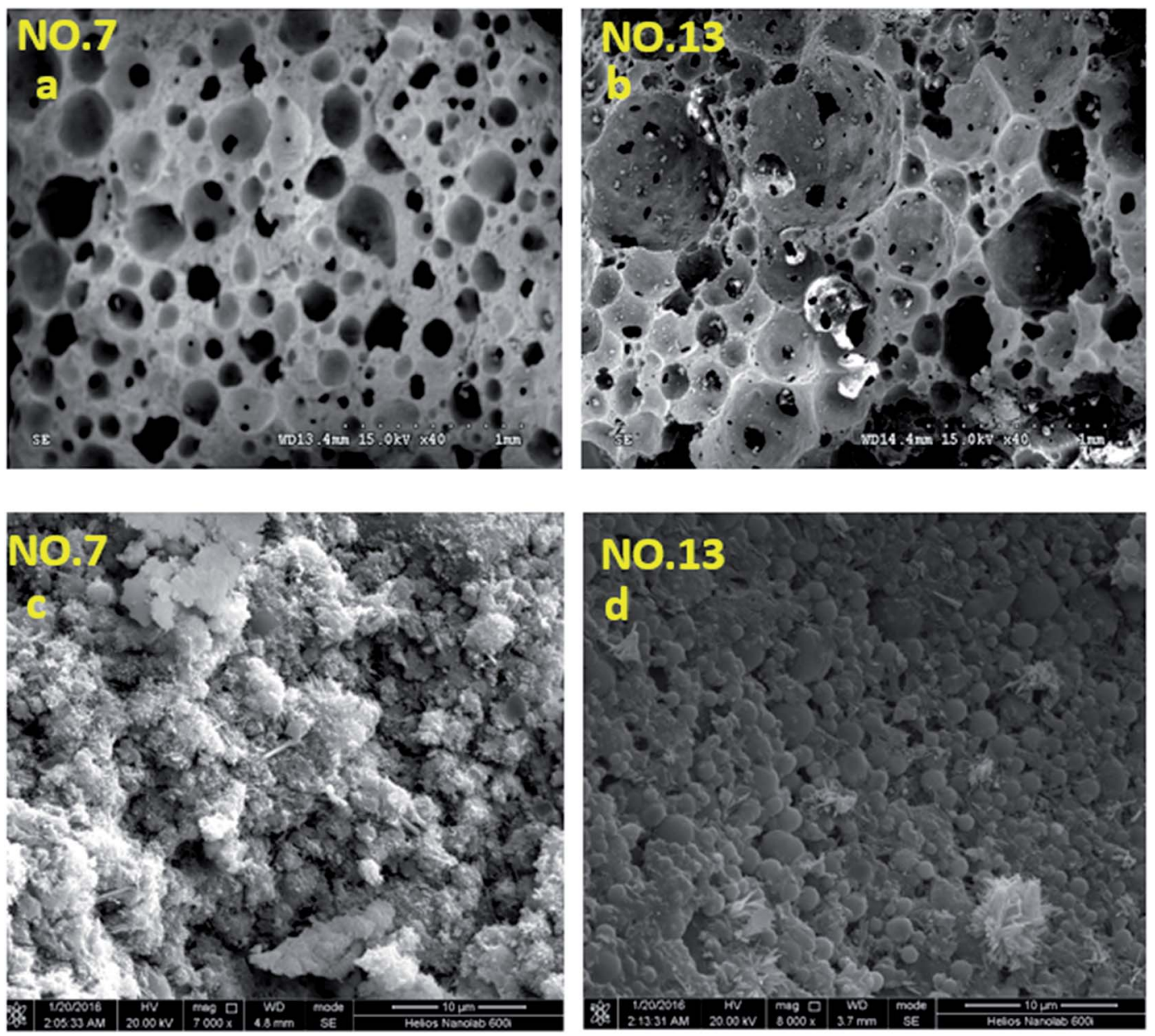

Fig. 7 SEM micrographs illustrating the different microstructure of mixes \#7 and \#13. 


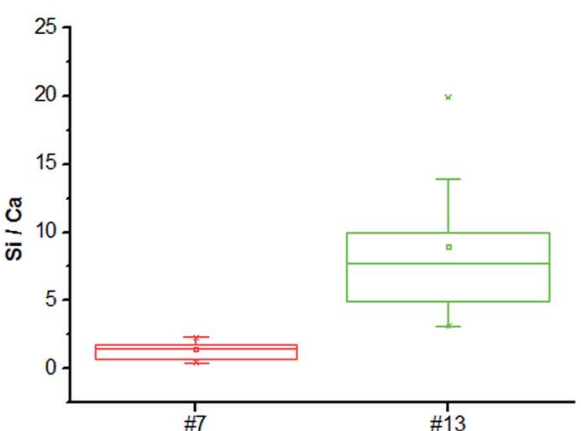

(a)

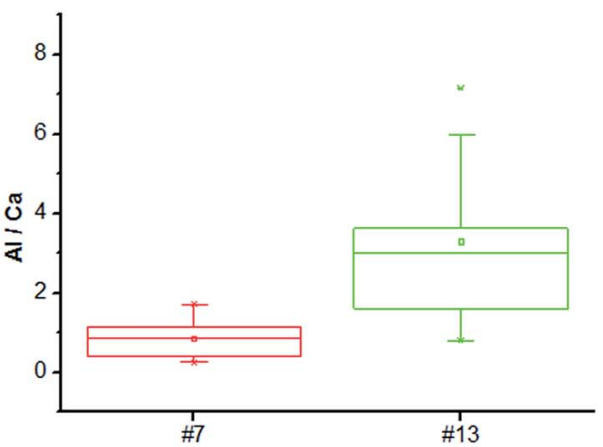

(b)

Fig. 9 Box plots of Si/Ca (a) and $\mathrm{Al} / \mathrm{Ca}$ (b) molar ratio in the hardened mixes \#7 and \#13.

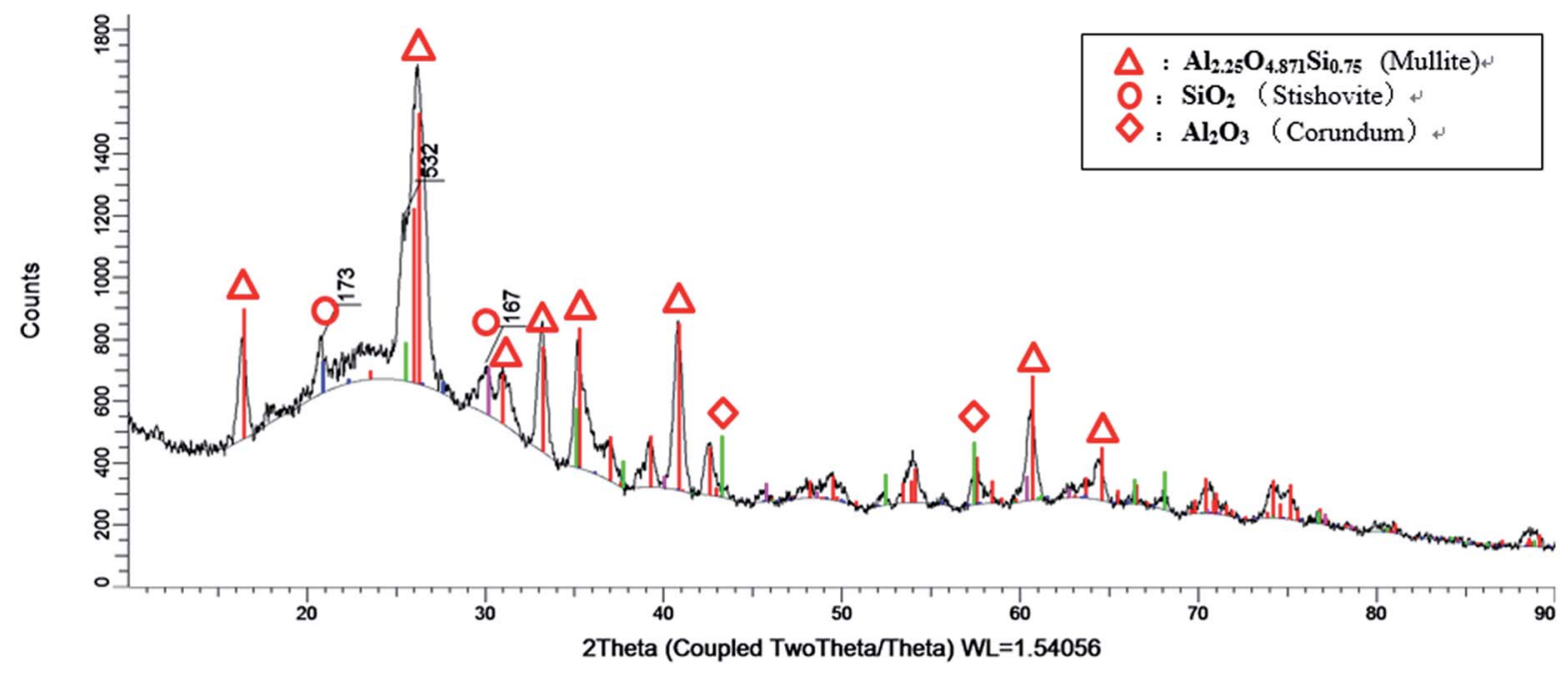

(a)

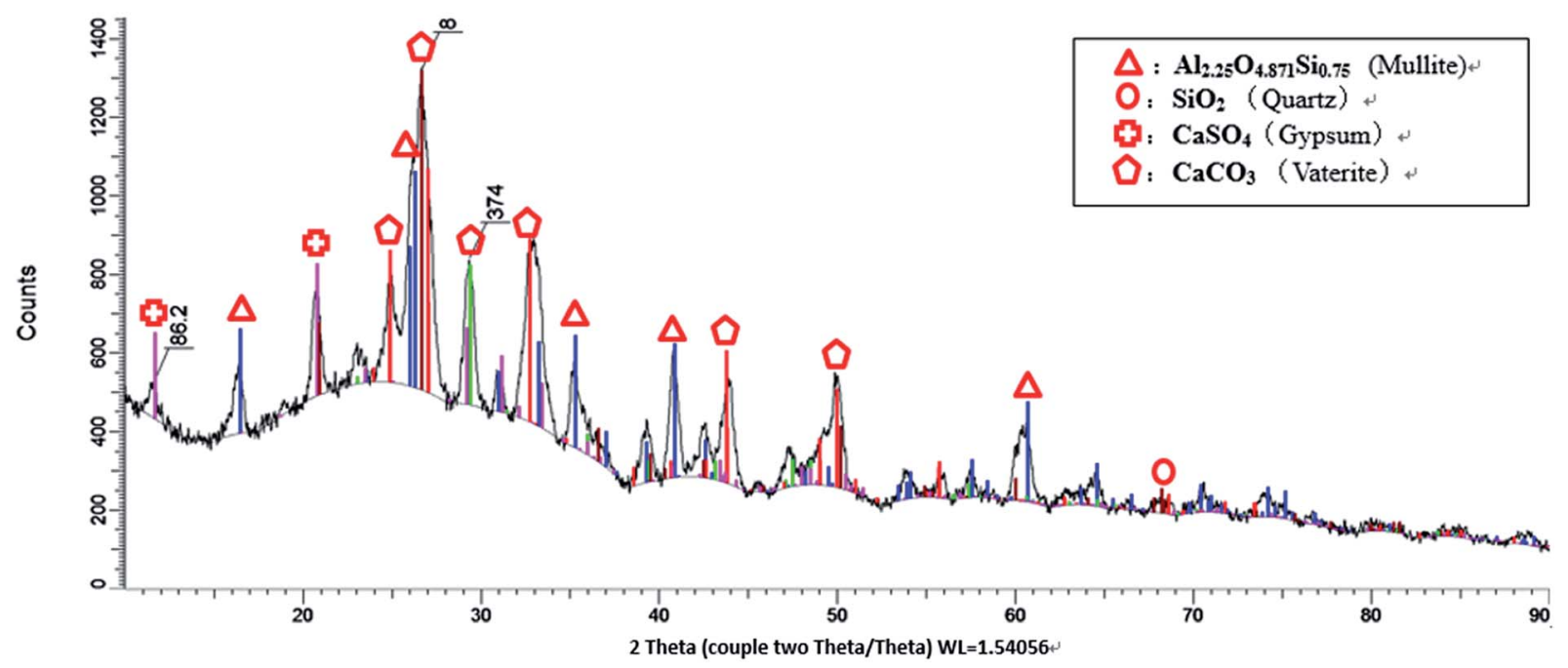

(b)

Fig. 10 XRD results of (a) coal fly ash and (b) HVFA foamed paste. 


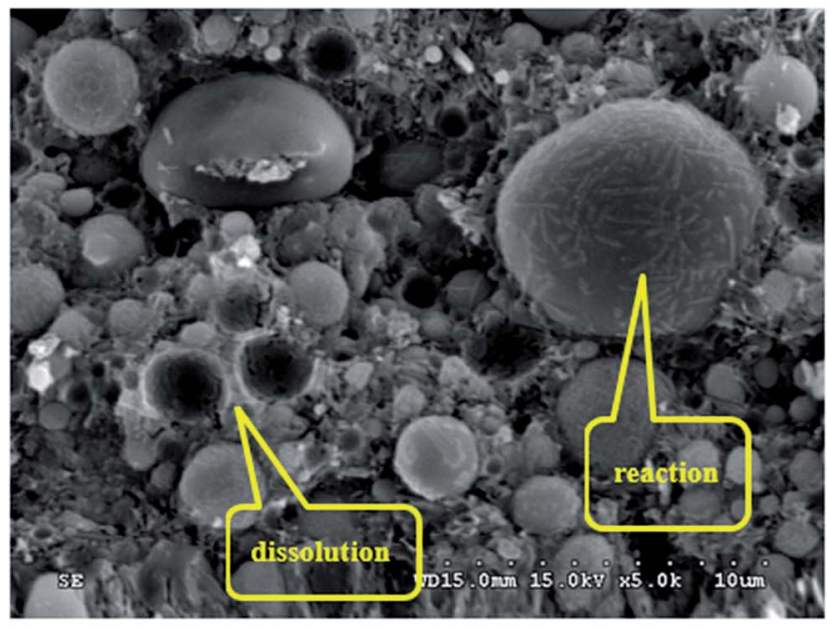

(a)

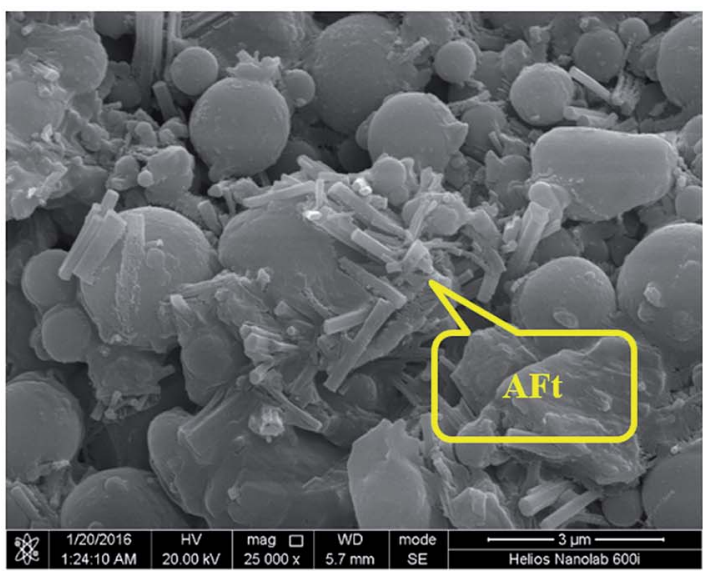

(b)

Fig. 11 SEM micrographs of hydrated mix \#7: (a) different levels of FA reaction; (b) detection of AFt phase.

\#7 exhibited significantly lower $\mathrm{Si} / \mathrm{Ca}$ and $\mathrm{Al} / \mathrm{Ca}$ ratios than mix $\# 13$, as shown in Fig. 9. These observed differences in the hydration products are likely due to the fact that mix \#7 used a 70\% FA+ $30 \%$ cement binder whereas mix \#13 used a 80\% FA + 20\% cement binder. The FA had a much lower $\mathrm{CaO}$ content but higher $\mathrm{SiO}_{2}$ and $\mathrm{Al}_{2} \mathrm{O}_{3}$ contents than the cement (Table 1). Fig. 9 also reveals that mix \#7 featured less scatter in its $\mathrm{Si} / \mathrm{Ca}$ and $\mathrm{Al} / \mathrm{Ca}$ ratios than mix \#13, implying more homogenous hydration products.

To further investigation the hydration mechanism of HVFC foamed paste, XRD was employed to analyze the crystalline phases in the fly ash and the hardened mix \#7 (with 70\% FA, 1\% AOS, 2\% AEO, $0.75 \% \mathrm{Na}_{3} \mathrm{PO}_{4}$, and 1\% nMMT). Both samples were tested in the power form. There are some obvious differences in the phase compositions of these two as well. Fig. 10a reveals that the main crystalline phases in the fly ash include mullite $\left(\mathrm{Al}_{2.25} \mathrm{O}_{4.871} \mathrm{Si}_{0.75}\right)$, corundum $\left(\mathrm{Al}_{2} \mathrm{O}_{3}\right)$ and stishovite $\left(\mathrm{SiO}_{2}\right)$. Fig. 10b reveals that the main crystalline phases in the foamed HVFA paste include mullite, quartz $\left(\mathrm{SiO}_{2}\right)$, gypsum $\left(\mathrm{CaSO}_{4}\right)$, and vaterite $\left(\mathrm{CaCO}_{3}\right)$. The comparison reveals that the corundum and stishovite phases and part of the mullite phase in the fly ash were consumed by their hydration. The hydration of corundum and stishovite phases likely entailed their reaction with cement and water to form $\mathrm{C}-\mathrm{S}-\mathrm{H}$ gel, which provides strength to the hardened HVFA foamed paste. The hydration of mullite entails the reaction of $\mathrm{Si}$ and $\mathrm{Al}$ elements with alkali to form $\mathrm{Si}-\mathrm{O}$ and $\mathrm{Al}-\mathrm{O}$ bonds. ${ }^{32}$ The mullite peaks (at around $16^{\circ}, 26^{\circ}, 35^{\circ}, 41^{\circ}$ and $61^{\circ}$ ) exhibited a reduced signal in the foamed paste than in the fly ash, which can be attributed to either its consumption by reaction with cement and water or its reduced crystallinity by such reaction (as revealed by SEM observations shown in Fig. 11). The mullite peak at around $26^{\circ}$ exhibited a wider peak in the foamed paste than in the fly ash, suggesting reduced grain size due to hydration. Note that crystalline phases in the fly ash are generally less reactive than amorphous phases. The presence of gypsum in the foamed paste can be traced back to the composition of cement. The presence of vaterite in the foamed paste is likely attributable to the reaction of airborne $\mathrm{CO}_{2}$ with one of the cement hydration products, portlandite.

Fig. 11a reveals that in the hydrated mix \#7 some FA particles were fully consumed by the hydration while others maintained their spherical structure and only reacted on its surface. This highlights the need to explore methods to enhance the hydration of fly ash particles in such HVFA foamed paste. Fig. 11b reveals the presence of rod-like AFt phase in the hydrated mix \#7, which is a hydration product of cement, ${ }^{33}$ but not detected in the XRD results (Fig. 10b).

\section{Conclusions}

This laboratory study explores a cost-effective and environmental friendly foamed paste made by using a high volume of class F coal fly ash as replacement of Portland cement (70\% by mass) and nano-montmorillonite as an admixture. A statistical design of experiments was adopted and executed to investigate the effects of various factors on the properties of the composite, with water/binder ratio of 0.3 . The key findings are as follows.

(1) Mix \#7 (with 70\% FA, 1\% AOS, 2\% AEO, 0.75\% $\mathrm{Na}_{3} \mathrm{PO}_{4}$, and $1 \%$ nMMT) exhibited the lowest thermal conductivity $\left(0.071 \mathrm{~W}\left(\mathrm{~m}^{-1} \mathrm{~K}^{-1}\right)\right)$ yet reasonably high strength $(3.23 \mathrm{MPa})$ at 28 days, representing the best TIMs among the mixtures investigated. Relative to the worst mix (without nMMT), this hardened mix featured a more homogeneous microstructure and more crystalline phases.

(2) The thermal conductivity of the foamed paste decreased linearly with the use of each foaming agent but was not significantly affected by the dosage of $\mathrm{FA}, \mathrm{Na}_{3} \mathrm{PO}_{4}$, or nMMT in the mix. Their $28 \mathrm{~d}$ compressive strength generally benefited from the use of a lower FA replacement level, lower AOS and $\mathrm{Na}_{3} \mathrm{PO}_{4} \mathrm{~d}$ dosages, and a higher nMMT dosage (up to $3 \%$ ).

(3) The XRD results reveal that the corundum and stishovite phases and part of the mullite phase in the fly ash were consumed by their hydration. There is the need to explore methods to enhance the hydration of fly ash particles in such HVFA foamed paste.

\section{Acknowledgements}

This work was supported by National Natural Science Foundation of China (Grant No. 51278390), Hubei Department of 
Education (ChuTian Scholar Visiting Professorship awarded to Wuhan Polytechnic University), and Hubei Provincial Department of Construction (Construction Science and Technology Plan Project EJB-2016-347-1-13).

\section{References}

1 K. S. Al-Jabri, A. W. Hago, A. S. Al-Nuaimi and A. H. Al-Saidy, Cem. Concr. Res., 2005, 35, 1472.

2 P. Barnes, and J. Bensted, Structure and performance of cements, CRC Press, 2000.

3 H. Binici and O. Aksogan, J. Mater. Cycles Waste Manage., 2015, 17, 157.

4 T. P. Chang, J. Y. Shih, K. M. Yang and T. C. Hsiao, J. Mater. Sci., 2007, 42, 7478.

5 I. D. L. Varga, R. P. Spragg, C. D. Bella, J. Castro, D. P. Bentz and J. Weiss, Cem. Concr. Compos., 2014, 45, 102.

6 P. Dinakar, K. G. Babu and M. Santhanam, Cem. Concr. Compos., 2008, 30, 880.

7 A. Zhang, Z. Li and L. Liu, Mixture Proportion Designing of Foam Concrete with Addition of Fly Ash and Calcium Carbide Sludge, in Proceedings of the 2012 Second International Conference on Electric Technology and Civil Engineering, IEEE Computer Society, May 2012, pp. 17221725.

8 N. Farzadnia, A. A. A. Ali, R. Demirboga and M. P. Anwar, Cem. Concr. Res., 2013, 48, 97.

9 B. Harwalkar and S. S. Awanti, J. Transp. Res. Board, 2014, 2441, 121.

10 X. He and X. Shi, J. Transp. Res. Board, 2008, 2070, 13.

11 F. Hiromi and T. Wee, J. Wuhan Univ. Technol., Mater. Sci. Ed., 2007, 22, 295.

12 N. M. Ibrahim, S. Salehuddin, R. C. Amat, L. N. Rahim and N. T. T. Izhar, APCBEE Proc., 2013, 5, 497.

13 E. P. Kearsley and P. J. Wainwright, Cem. Concr. Res., 2001, 31, 105.

14 E. P. Kearsley and P. J. Wainwright, Cem. Concr. Res., 2002, 32, 233.

15 W. Y. Kuo, J. S. Huang and C. H. Lin, Cem. Concr. Res., 2006, 36, 886-895.
16 S. K. Lim, C. S. Tan, O. Y. Lim and Y. L. Lee, Construct. Build. Mater., 2013, 46, 39.

17 G. Masi, W. D. Rickard, L. Vickers, M. C. Bignozzi and A. V. Riessen, Ceram. Int., 2014, 40, 13891.

18 P. K. Mehta, High-performance, high-volume fly ash concrete for sustainable development, in Proceedings of the international workshop on sustainable development and concrete technology, Iowa State University, Ames, IA, USA, May 2004, pp. 3-14.

19 M. A. O. Mydin and Y. C. Wang, Construct. Build. Mater., 2012, 26, 638.

20 T. R. Naik, S. S Singh and M. M Hossain, Cem. Concr. Res., 1994, 24, 913.

21 N. Yang, J. Chin. Ceram. Soc., 1996, 4, 209.

22 A. Palomo, M. W. Grutzeck and M. T. Blanco, Cem. Concr. Res., 1999, 29(8), 1323-1329.

23 C. E. Roskos, Building green: development and evaluation of an environmentally friendly concrete, Doctoral dissertation, Montana State University, College of Engineering, Bozeman, 2011.

24 G. Sang, Y. Zhu, G. Yang and H. Zhang, Construct. Build. Mater., 2015, 91, 133.

25 M. Schneider, M. Romer, M. Tschudin and H. Bolio, Cem. Concr. Res., 2011, 41, 642.

26 X. Shi, L. Fay, M. M. Peterson, M. Berry and M. Mooney, Construct. Build. Mater., 2011, 25, 957.

27 X. Shi, Z. Yang, Y. Liu and D. Cross, Construct. Build. Mater., 2011, 25, 3245.

28 A. A. Stec and T. R. Hull, Energ. Build., 2011, 43, 498.

29 P. Torkittikul, T. Nochaiya, W. Wongkeo and A. Chaipanich, J. Mater. Cycles Waste Manage., 2015, 34, 1.

30 P. V. D. Heede, E. Gruyaert and N. D. Belie, Cem. Concr. Compos., 2010, 32, 749.

31 Z. T. Yao, X. S. Ji, P. K. Sarker, J. H. Tang, L. Q. Ge, M. S. Xia and Y. Q. Xi, Earth-Sci. Rev., 2015, 141, 105.

32 M. Şahmaran, İ. Ö. Yaman and M. Tokyay, Cem. Concr. Compos., 2009, 31, 99.

33 S. Zhang, X. Hu, X. Wang, S. Liang and L. Wu, Chin. J. Catal., 2002, 33, 1736. 